\title{
Evaluation of Natural Slope Stability using Digital Elevation Models and Satellite Imagery
}

\author{
Takehiro OHTA, Dr. Sci. \\ Senior Researcher, \\ Atsushi HASEGAWA \\ Geology Laboratory, Disaster Prevention Technology Division \\ Hideaki ENOMOTO \\ Senior Researcher, Laboratory Head, \\ Geology Laboratory, Disaster Prevention Technology Division
}

(Temporarily transferred to JR East)

\begin{abstract}
Natural disasters are not only by geomorphologic, geologic and hydrogeologic conditions but also by vegetation and artificial civil workings. These conditions can be evaluated qualitatively based on aerial photography analyses and field surveys. The quantitative evaluation of natural slope stability is carried out using digital elevation models (DEMs) and high-resolution satellite imagery. In the homogeneous geologic condition area, DEMs can detect the geomorphologic features involved in natural disasters, and satellite imagery can evaluate vegetation. Therefore, we consider that natural slope stability is estimable by a combination of geomorphologic attributes calculated from DEMs and vegetation indices obtained from satellite imagery.
\end{abstract}

Keywords: natural slope, slope stability, digital elevation model, satellite imagery, vegetation

\section{Introduction}

Not only geomorphologic, geologic and hydrogeologic conditions but also vegetation and artificial civil workings have caused natural disasters. Some scientists have discussed the relationship between slope disasters and geomorphology ${ }^{1)}$. Recently, researchers have attempted to evaluate quantitatively the geomorphologic conditions concerning slope disasters, and to predict the points where slope disasters are most likely to occur ${ }^{2}$. It is however difficult to assess the occurrences of natural disasters quantitatively and accurately solely by the geomorphology. Therefore, it is necessary to establish a quantitative assessment method for natural disasters that takes into account not only geomorphology but also environmental conditions such as vegetation.

The relation between geomorphology and vegetation has been discussed in terms of geoecology for the purpose of ecological preservation. Kikuchi ${ }^{3)}$ discussed the features and formation processes of vegetation in the area of slope failures and debris-flow deposits. However, geoecological studies have only discussed the formation of vegetation in the present geomorphology. In the forestry field, there are some studies on the recovery process of vegetation after slope failure that uses aerial photographs ${ }^{4)}$. As mentioned above, in all study fields there are few cases that discuss the relation between the change of vegetation environment and natural slope disasters. On the other hand, vegetation conditions have been assessed quantitatively since the 1970 s by the analysis of satellite imagery such as that from LANDSAT. It has become possible to evaluate vegetation conditions in detail using high-resolution satellite imagery in recent years ${ }^{5}$.

To understand the degree of effect on geomorphology, geology, hydrogeology and vegetation for the occurrence of natural slope disaster/s, we investigated these features of an area where natural disasters had occurred by a field survey, an aerial photograph reading, a morphometric measure using a digital elevation model (DEM), a slope stability analysis and a satellite imagery analysis. This paper contains the evaluation method of natural slope stability by DEM and satellite imagery, based on the investigation's results.

\section{Quantitative geomorphologic conditions related with natural slope stability}

In this Chapter, we explain the relationship between natural slope stability and topographic parameters calculated from DEMs in consideration of geomorphology, geology and hydrogeology.

\subsection{Geomorphologic feature relevant to slope stability}

To obtain the quantitative geomorphologic parameters for slope stability, the distribution of topographic parameters calculated from DEMs was compared with that of an unstable slope sampled by aerial photography, because geology generally controls geomorphologic features. The site of this examination is in the northern Kitakami Mountains region (Fig. 1). Mesozoic sedimentary rocks such as shale, sandstone and chert are distributed in this area and these facies can be regarded as a homogeneous geologic condition. In the past, there have been many natural disasters such as rock falls, slope failures and debrisflows in this area.

We measured the topographic parameters of each drainage basin in Fig. 1 from the DEM, obtained by laser profiling with DEM grid intervals of $5 \mathrm{~m}$. In addition, the 


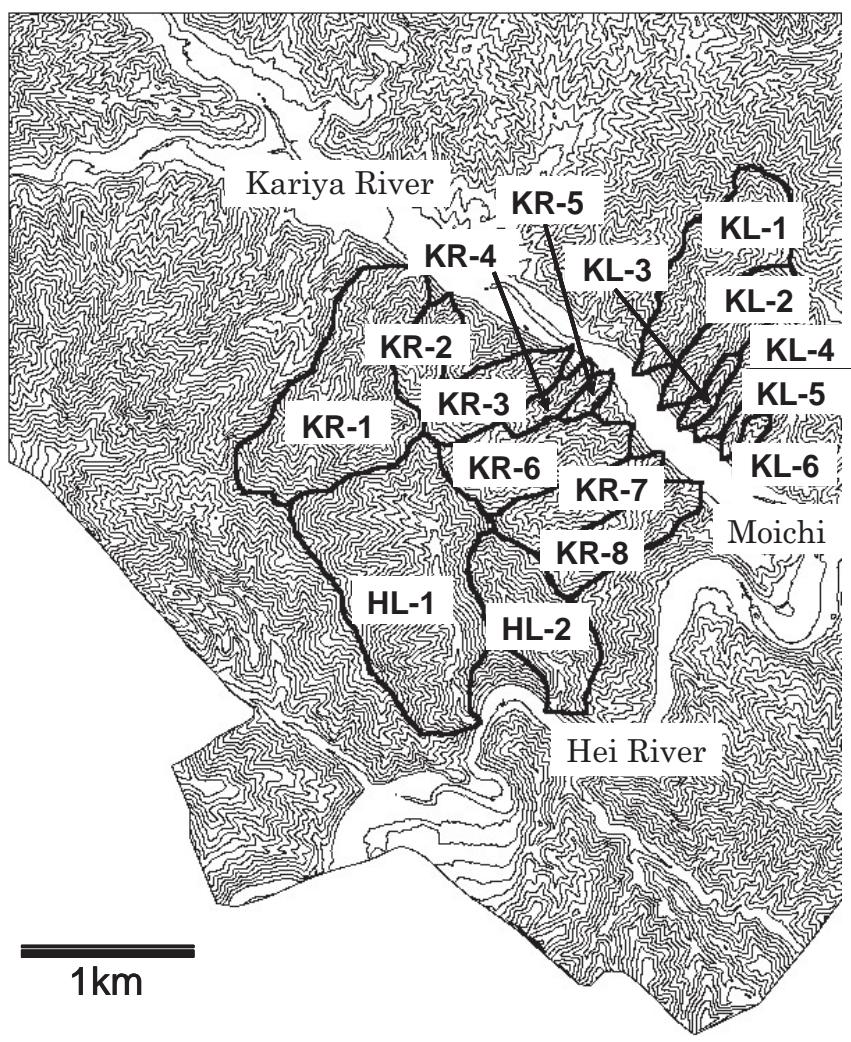

Fig. 1 Topographical map of examination site and drainage basin distribution

marks of topographic damage (slope failures, gullies and debris-flow deposits) were discerned from aerial photographs. Table 1 shows the results. Many topographic parameters are related to the area of the drainage basin. Therefore, Fig. 2 shows the number of slope failures against only the basin area, the ratio of surface area to basin area and the average maximum slope angle. The number of slope failures increases incrementally accord-
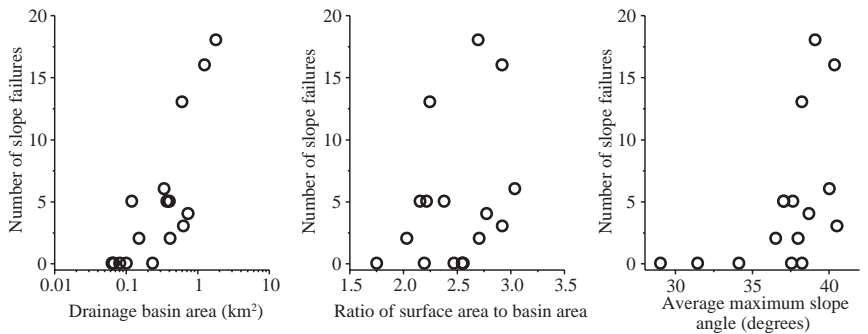

Fig. 2 Relationship between topographic parameters and the number of slope failures

ing to the ratio of surface area to basin area and the average maximum slope angle. If the average slope angle in the basin exceeds 37 degrees, there is a significant increase in the number of slope failures.

Many slope failures and debris-flow deposits are distributed in basins that cover large areas and have high average maximum slope angles (KR-1, HL-1). Therefore, it is conceivable that the topographic conditions are relevant to slope stability in drainage basins.

KR-6, KR-7 and KR-8 have similar topographic parameters. However, there are more slope failures, gullies and debris-flow deposits in KR-6 than in the other two drainage basins. Such a fact is suggestive that slope stability in the region is indeterminable solely by geomorphology under homogeneous geologic conditions.

\subsection{Relation between slope stability and topographic parameters reflecting hydrogeology}

To estimate the effect of hydrogeologic conditions on topographic parameters, we examined the relation between the slope safety ratio and topographic parameters in a hilly area in Akita Prefecture where Tertiary sandstone and siltstone are distributed.

We estimated the hydrogeologic conditions by undertaking a finite element analysis of saturated-unsaturated

Table 1 Topographic parameters and amount of topographic damage in the Kitakami Mountains

\begin{tabular}{|c|c|c|c|c|c|c|c|}
\hline \multirow[b]{2}{*}{$\begin{array}{l}\text { Drainage } \\
\text { Basin No. }\end{array}$} & \multicolumn{4}{|c|}{ Topographic parameters } & \multicolumn{3}{|c|}{ Amount of topographic damage } \\
\hline & $\begin{array}{l}\text { Area } \\
\left(\mathrm{km}^{2}\right)\end{array}$ & $\begin{array}{c}\text { Average } \\
\text { maximum } \\
\text { slope angle }\left(^{\circ}\right)\end{array}$ & $\begin{array}{l}\text { Ratio of surface } \\
\text { area to basin area }\end{array}$ & $\begin{array}{l}\text { Dispersions } \\
\text { of altitude } \\
\text { (m) }\end{array}$ & $\begin{array}{l}\text { Gully } \\
\text { length } \\
(\mathrm{km})\end{array}$ & $\begin{array}{c}\text { Number of } \\
\text { slope failures }\end{array}$ & $\begin{array}{c}\text { Area of debris- } \\
\text { flow deposit } \\
\left(\mathrm{km}^{2}\right)\end{array}$ \\
\hline HL-1 & 1.82 & 39.16 & 2.70 & 5.43 & 1.4 & 18 & 0.128 \\
\hline HL-2 & 0.64 & 40.57 & 2.92 & 5.63 & 3.3 & 3 & 0.017 \\
\hline KL-1 & 0.74 & 38.76 & 2.78 & 5.31 & 0.7 & 4 & 0.033 \\
\hline KL-2 & 0.35 & 40.09 & 3.04 & 5.61 & 0.5 & 6 & 0.023 \\
\hline KL-3 & 0.08 & 37.60 & 2.48 & 5.05 & 0.1 & 0 & 0.000 \\
\hline KL-4 & 0.15 & 38.03 & 2.72 & 5.21 & 0.7 & 2 & 0.000 \\
\hline KL-5 & 0.10 & 34.17 & 2.56 & 4.60 & 0.5 & 0 & 0.000 \\
\hline KL-6 & 0.06 & 29.06 & 1.84 & 3.53 & 0.6 & 0 & 0.000 \\
\hline KR-1 & 1.27 & 40.40 & 2.93 & 5.57 & 1.7 & 16 & 0.036 \\
\hline KR-2 & 0.24 & 38.31 & 2.57 & 5.20 & 0.4 & 0 & 0.003 \\
\hline KR-3 & 0.38 & 37.70 & 2.16 & 5.07 & 0.5 & 5 & 0.016 \\
\hline KR-4 & 0.12 & 37.12 & 2.39 & 4.90 & 0.2 & 5 & 0.003 \\
\hline KR-5 & 0.07 & 31.48 & 2.20 & 4.00 & 0.0 & 0 & 0.000 \\
\hline KR-6 & 0.62 & 38.28 & 2.26 & 5.16 & 1.7 & 13 & 0.023 \\
\hline $\mathrm{KR}-7$ & 0.42 & 36.58 & 2.04 & 4.90 & 1.3 & 2 & 0.003 \\
\hline KR-8 & 0.41 & 37.08 & 2.24 & 4.96 & 0.6 & 5 & 0.000 \\
\hline
\end{tabular}




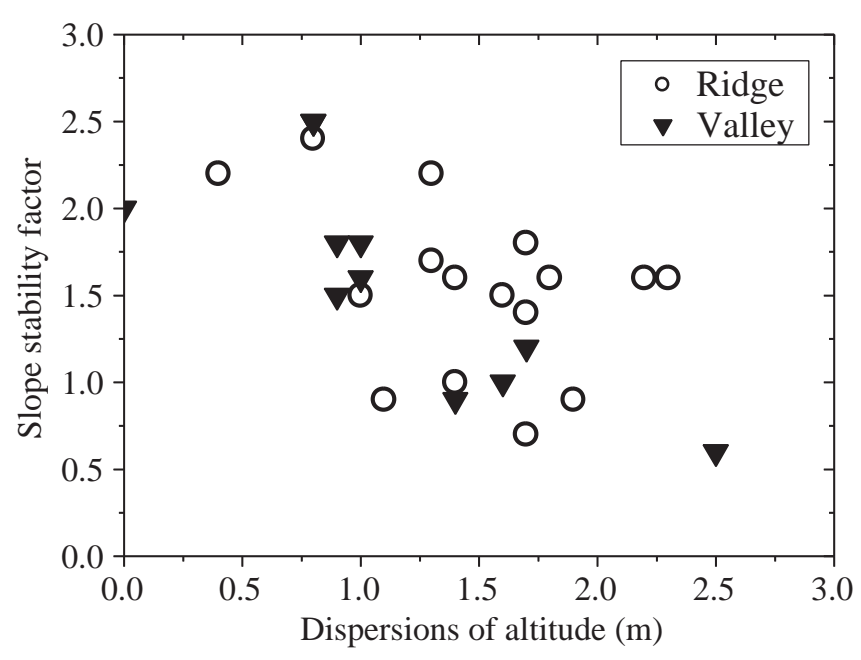

Fig. 3 Slope safety factor against dispersions of altitude (Ds)

seepage. Slope stability analysis took into account exceeded pore pressure, as estimated by the seepage analysis. Topographic parameters were calculated from a DEM obtained by laser profiling. The grid intervals of both the slope stability analysis and DEM analysis were $2 \mathrm{~m}$.

The slope safety factor decreases as the dispersions of altitude (Ds) increase (Fig. 3), making it conceivable that the slope safety factor could be estimated by the dispersion of altitude. Other topographic parameters also increase as the slope safety factor decreases.

These results indicate that some topographic parameters contain both geologic and hydrogeologic conditions. Therefore, it seems that slope stability is assessable from the slope safety factor estimated from topographic parameters.

\section{Quantitative vegetative conditions related to natural slope stability}

It is generally recognized that vegetation affects the stability of natural slopes because vegetation relates to a slope's ability to retain water and resist erosion. In this Chapter, we discuss the relationship between vegetation and slope stability and the quantitative evaluation of vegetative conditions.

\subsection{Vegetation change relevant to slope stability}

To understand the adverse effects of changes in vegetation on slope stability, the vegetative conditions and the distribution of topographic damage in the Kitakami Mountains shown in Fig. 1 were read from aerial photographs taken on six occasions between 1970 and 2001. According to the aerial photographs, the natural broadleaf forests were divided into the Quercus serrata/chestnut/deciduous broadleaf (Q-C-DB) forest community, the secondary forest (SF) community after felling and the red pine/deciduous broadleaf (RP-DB) forest community. Coniferous forests consisting of cedar and cypress were classified into young and old conifer forest $(\mathrm{CF})$ communities.

From changes in vegetation over time and the development of topographic damage, sixteen drainage basins were classified into five groups, as shown in Table 2. Fig. 4 illustrates the changes in vegetation distribution ratios over time and the change in topographic damage distribution in the KR-1 basin, classified in Group 1.

As shown in Table 2 and Fig. 4, the variations of topographic damage development in the drainage basins classified as Groups 1 and 4 have a good relation with changes in vegetation conditions. Therefore, we can regard vegetation as a factor in slope stability. However, topographic damage in the basins classified as Group 2 remarkably increased, though the vegetation conditions are constant. This suggests that basin geomorphology affects slope stability.

\subsection{Vegetation assessments using satellite imagery}

Satellite imagery of the Kitakami Mountains taken in April 2000 was analyzed to examine the assessment

Table 2 Drainage basin groupings based on changes in vegetation over time and topographic damage development

\begin{tabular}{|c|c|c|c|c|}
\hline Group & Drainage basin No. & Vegetation change & $\begin{array}{c}\text { Development of } \\
\text { topographic damage }\end{array}$ & Topographic feature \\
\hline 1 & HL-1, KL-1, KR-1 & $\begin{array}{l}\text { Remarkable changes in } \\
\text { distribution ratios of some } \\
\text { communities }\end{array}$ & $\begin{array}{l}\text { Large variations in } \\
\text { topographic damage } \\
\text { development }\end{array}$ & $\begin{array}{l}\text { Large basin area } \\
\text { Large ratio of surface area to basin } \\
\text { area }\end{array}$ \\
\hline 2 & HL-2, KL-2 & $\begin{array}{l}\text { Constant distribution ratio } \\
\text { (more than } 80 \% \text { ) in } \\
\text { deciduous broadleaf forest } \\
\text { community }\end{array}$ & $\begin{array}{l}\text { Large variations in } \\
\text { topographic damage } \\
\text { development }\end{array}$ & $\begin{array}{l}\text { Large ratio of surface area to basin } \\
\text { area }\end{array}$ \\
\hline 3 & KL-5, KR-5, KR-8 & $\begin{array}{l}\text { Felling of deciduous broad- } \\
\text { leaf forest since } 1990\end{array}$ & Almost no change & No common feature \\
\hline 4 & KR-3, KR-4, KR-6 & $\begin{array}{l}\text { Felling of deciduous broad- } \\
\text { leaf forest since } 1990\end{array}$ & $\begin{array}{l}\text { Increase in topographic } \\
\text { damage after } 1995\end{array}$ & $\begin{array}{l}\text { Medium basin area with small ratio } \\
\text { of surface area to basin area } \\
\text { Small basin area with medium ratio } \\
\text { of surface area to basin area }\end{array}$ \\
\hline 5 & $\begin{array}{c}\text { KL-3, KL-4, KL-6, } \\
\text { KR-2, KR-7 }\end{array}$ & No change & No change & Small basin area \\
\hline
\end{tabular}




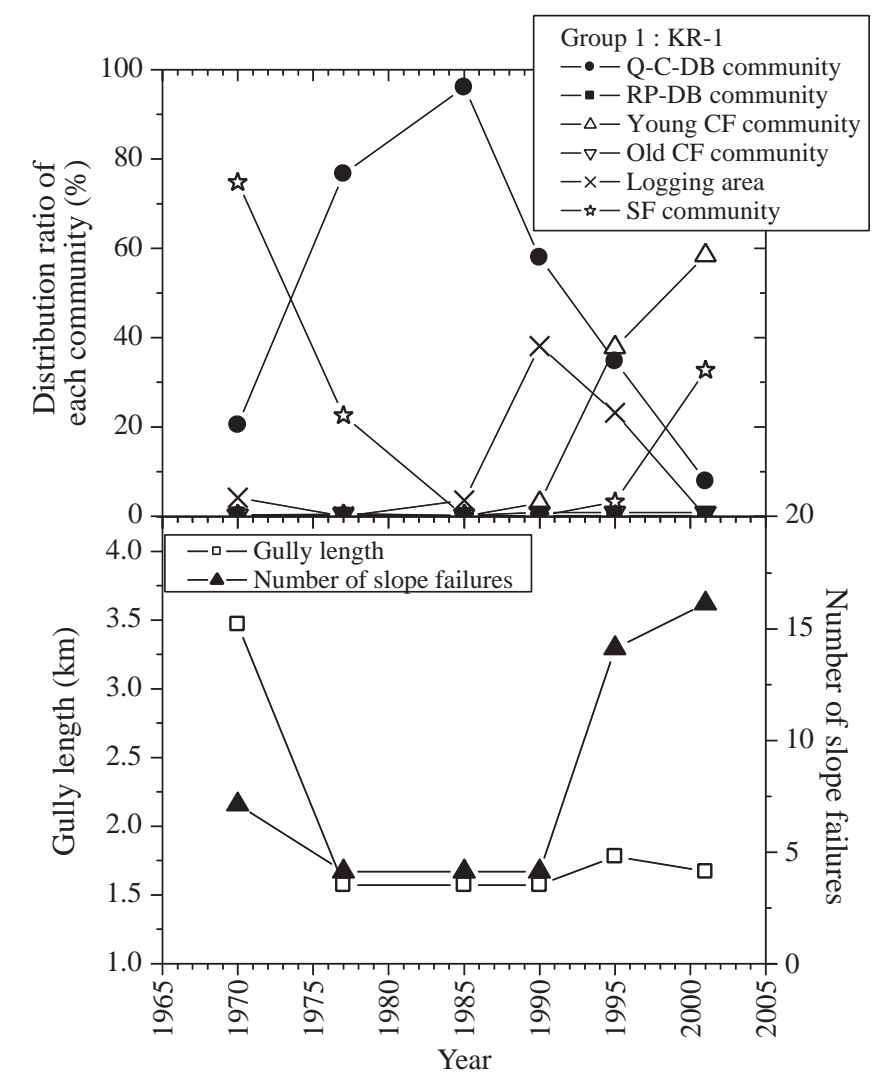

Fig. 4 Changes in vegetation over time and development of topographic damage in Group 1 drainage basin: KR-1

method of vegetative conditions.

Artificial structures, the river and the forest are easily detectable by true and false color images. Evergreen forest is distinguished from deciduous forest as the images were taken during the leaf fall period. However, the deciduous forest is undistinguishable from the logging area and secondary forest because the images show these three vegetation conditions in the same color.

Vegetation reflects near-infrared rays in sunlight, and red rays are absorbed into the vegetation. Therefore, it is possible to evaluate vegetative conditions by near-infrared and red ray imagery. The normalized differential vegetation index (NDVI) is normally applicable to vegetation classifications, and is calculated from the near-infrared and red ray reflectance spectra (Equation 1) ${ }^{6}$ )

$$
N D V I=\left\{\frac{1+(\text { nir }- \text { red })}{1+(\text { nir }+ \text { red })}\right\} \times C
$$

where nir is the near-infrared ray reflection spectra and red is the red ray reflectance spectra. $C$ is constant.

The NDVI becomes high values in areas where vegetation is highly developed and indicates lower values in areas with little or no vegetation cover such as rivers, roads and logging areas. Fig. 5 shows the NDVI image of the Kitakami Mountains, in which the dark gray areas correspond to logging areas and the light gray areas indicate deciduous broadleaf forests. White areas show the forested conifer forests. From these results, satellite imagery can be considered a useful tool for vegetation as-

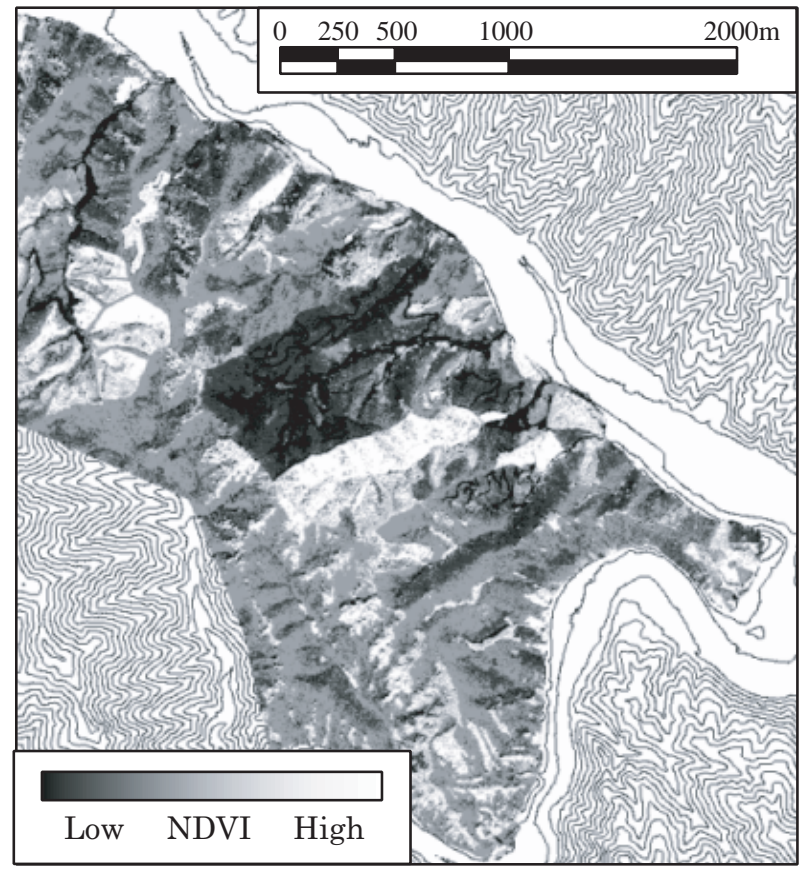

Fig. 5 NDVI image of the Kitakami Mountains

sessments.

\subsection{Assessment of vegetative inertance}

Because both vegetation and geomorphology affect slope stability, as mentioned above, it is effective to assess slope stability from both the vegetative condition and geomorphologic condition standpoints. Slope stability decreases as the topographic parameters (e.g. the ratio of surface area to basin area, the maximum slope angle) increase. In addition, stability reduces as vegetation is inactivated. The NDVI value shows the degree of vegetation activity and falls with the increase of vegetative inertance.

To assess the slope stability, it is effective to assess the vegetative conditions by the value that increases with vegetative inertance. Therefore, we use the reverse-normalized differential vegetation index (rNDVI), as shown in Equation 2, to assess vegetation conditions

$$
r N D V I=\left\{\frac{1+(\text { red }- \text { nir })}{1+(\text { nir }+ \text { red })}\right\} \times C
$$

where nir is the near-infrared ray reflection spectra and red is the red ray reflectance spectra. $C$ is constant. From Equations 1 and 2, the histogram of rNDVI has an axisymmetric relation with that of NDVI.

\section{Assessment of natural slope stability by DEM and satellite imagery}

We attempted to assess slope stability using both Ds calculated from DEM and the rNDVI derived from satellite imagery. The Ds include geomorphologic conditions, geologic conditions and hydrogeologic conditions. Fig. 6(a) indicates the distribution of values that multiplied the 


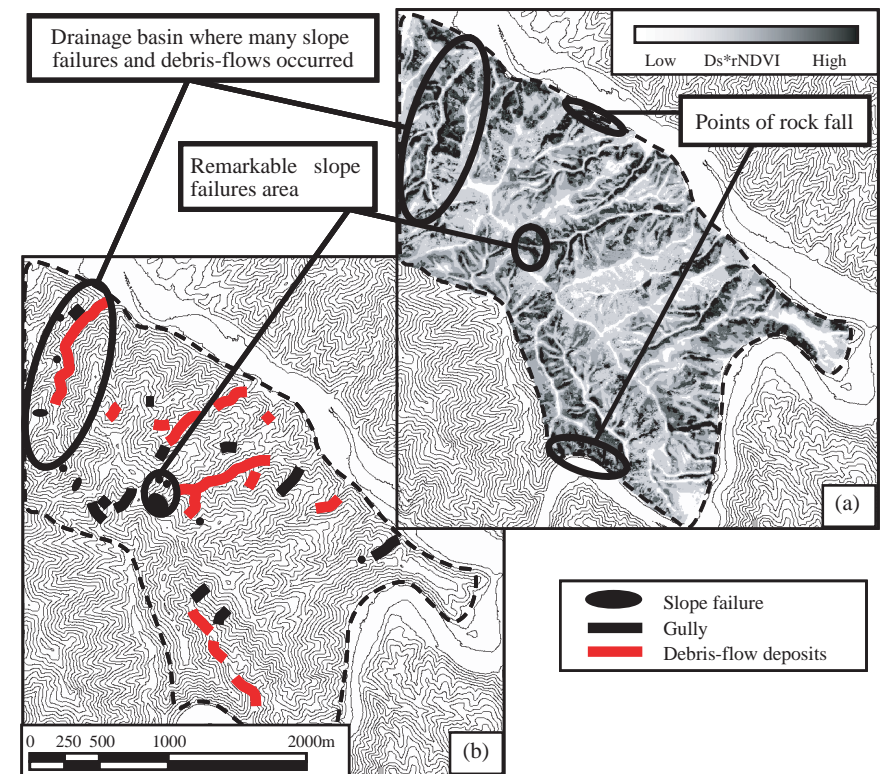

Fig. 6 Imagery of Ds*rNDVI value (a) and distribution of topographic damage (b)

Ds and the rNDVI. This value, subsequently referred to as Ds*rNDVI, is high when vegetation is thin on steep slope areas and low in thickly covered flat slope areas. Comparing the image of Ds*rNDVI values in Fig. 6(a) with the topographic damage distribution in Fig. 6(b), topographic damage is frequently seen in areas at where the values are high.

Fig. 7 shows the relation between the Ds*rNDVI values and the amount of topographic damage in each drainage basin. As shown in this figure, it is evident that topographic damage increases with increases in the Ds*rNDVI value.

From these results, the Ds*rNDVI value can be considered as an indicator of natural slope stability. Therefore, we propose to assess slope stability using both topographic parameters calculated from DEMs and vegetative factors derived from satellite imagery.

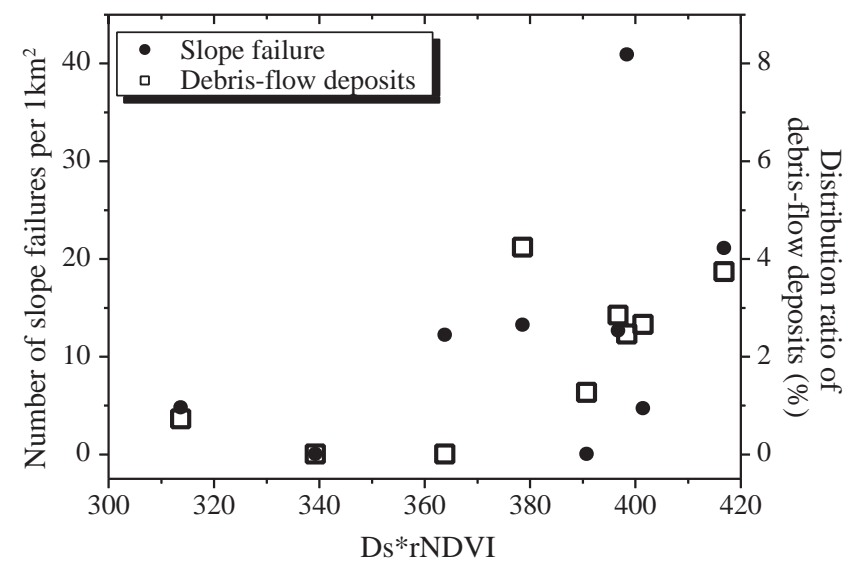

Fig. 7 Development of topographic damage against Ds*rNDVI value

\section{Conclusions}

To understand how much of an effect geomorphology, geology, hydrogeology and vegetation have on the occurrence of natural slope disasters, we performed a field survey, an aerial photograph reading, a morphometric measure using a DEM, a slope stability analysis and a satellite imagery analysis at several locations. The results were as follows:

(1) In many cases, geomorphologic conditions affect slope stability.

(2) Some topographic parameters include not only geomorphologic conditions but also geologic and hydrogeologic conditions and can indicate roughly the slope safety factor.

(3) Vegetative cover conditions influence slope stability in the same way as geomorphologic conditions.

(4) NDVI images from satellite imagery are useful to assess the vegetation.

Based on these results, we examined a slope stability assessment method that uses DEMs and satellite imagery. The value obtained from multiplying the Ds and the rNDVI corresponded to the amount of topographic damage. Therefore, it is available to evaluate slope stability from topographic parameters calculated by DEM and the vegetative cover factor derived from satellite imagery.

\section{Acknowledgements}

The authors would like to express their sincere gratitude to Dr. Hideo Kiya for his advice on engineering geology. The authors also thank the entire staff of the Geology Group for their assistance.

\section{References}

1) Varnes, D.J., "Slope movement type and processes," in Landslides Analysis and Control (R.L. Schuster and R.J. Krizek, Eds.), National Research Council, Transportation Research Board, Special Report, No. 176, pp. 11-33, 1978

2) Ohta, T and Kiya, H., "Evaluation of disaster by geomorphometry using digital elevation model," RTRI Report, Vol. 17, No. 8, pp. 37-42, 2003 (in Japanese)

3) Kikuchi, T., Vegetation and Landforms. University of Tokyo Press, p. 220, 2001 (in Japanese)

4) Suzuki, M., "Fifty-seven years monitoring bare land and vegetation covering the northern Tanzawa Mountains using aerial photography," Journal of Japan Society of Erosion Control Engineering, Vol. 54, No. 5, pp. 12-19, 2002 (in Japanese)

5) Kawamura, M., Tsujino, K. and Tsujiko, Y., "Development of a forest species classification method based on a decision tree method using high resolution satellite imagery," Journal of Japan Society of Photogrammetry and Remote Sensing, Vol. 44, No. 2, pp. 54-67, 2005(in Japanese)

6) Rouse, J. W., Haas, R. H., Schell, J. A. and Deering, D. W., "Monitoring Vegetation Systems in the Great Plains with ERTS," in Proceedings of Third Earth Resources Technology Satellite - 1 Symposium, Greenbelt, NASA SP-351, pp.301-317, 1974 